SUPPORTING INFORMATION

\title{
SELECTIVE CONTROL OF ION TRANSPORT BY NANO-CONFINEMENT: IONIC LIQUID IN MESOPOROUS RESORCINOL-FORMALDEHYDE MONOLITH
}

Carl-Philipp Elverfeldt, Young Joo Lee* and Michael Fröba*

Institute of Inorganic and Applied Chemistry, University of Hamburg, Martin-Luther-KingPlatz 6, 20146 Hamburg, Germany.

Corresponding authors.

*michael.froeba@chemie.uni-hamburg.de

*lee@chemie.uni-hamburg.de

1. Synthetic detail

2. Analysis of pore size distribution using different methods

3. DSC

4. Ionic conductivity

5. Diffusion coefficients

6. ${ }^{7}$ Li MAS NMR of PRFM filled with electrolytic solution 


\section{SYNTHETIC DETAIL}

Table S1. Amounts of reactants used for the synthesis of porous polymer monoliths.

\begin{tabular}{|l|l|l|l|l|l|}
\hline Sample & $m_{\text {resorcinol }}$ & $V_{\text {formaldehyde }}$ & $V_{\mathrm{HCl}}(0.01 \mathrm{M})$ & $V_{\text {ethanol }}$ & $n(\mathrm{EtOH}) / n\left(\mathrm{H}_{2} \mathrm{O}\right)$ \\
\hline PRFM-2.00 & 2.00 & 3.00 & 3.00 & 2.00 & 0.206 \\
\hline PRFM-1.75 & 2.00 & 3.00 & 3.00 & 1.75 & 0.180 \\
\hline PRFM-1.70 & 2.00 & 3.00 & 3.00 & 1.70 & 0.175 \\
\hline PRFM-1.60 & 2.00 & 3.00 & 3.00 & 1.60 & 0.165 \\
\hline PRFM-1.40 & 2.00 & 3.00 & 3.00 & 1.40 & 0.144 \\
\hline PRFM-1.35 & 2.00 & 3.00 & 3.00 & 1.35 & 0.139 \\
\hline PRFM-1.25 & 2.00 & 3.00 & 3.00 & 1.25 & 0.129 \\
\hline PRFM-1.20 & 2.00 & 3.00 & 3.00 & 1.20 & 0.124 \\
\hline PRFM-1.10 & 2.00 & 3.00 & 3.00 & 1.10 & 0.113 \\
\hline PRFM-0.70 & 2.00 & 3.00 & 3.00 & 0.70 & 0.072 \\
\hline
\end{tabular}




\section{ANALYSIS OF PORE SIZE DISTRIBUTION USING DIFFERENT METHODS}

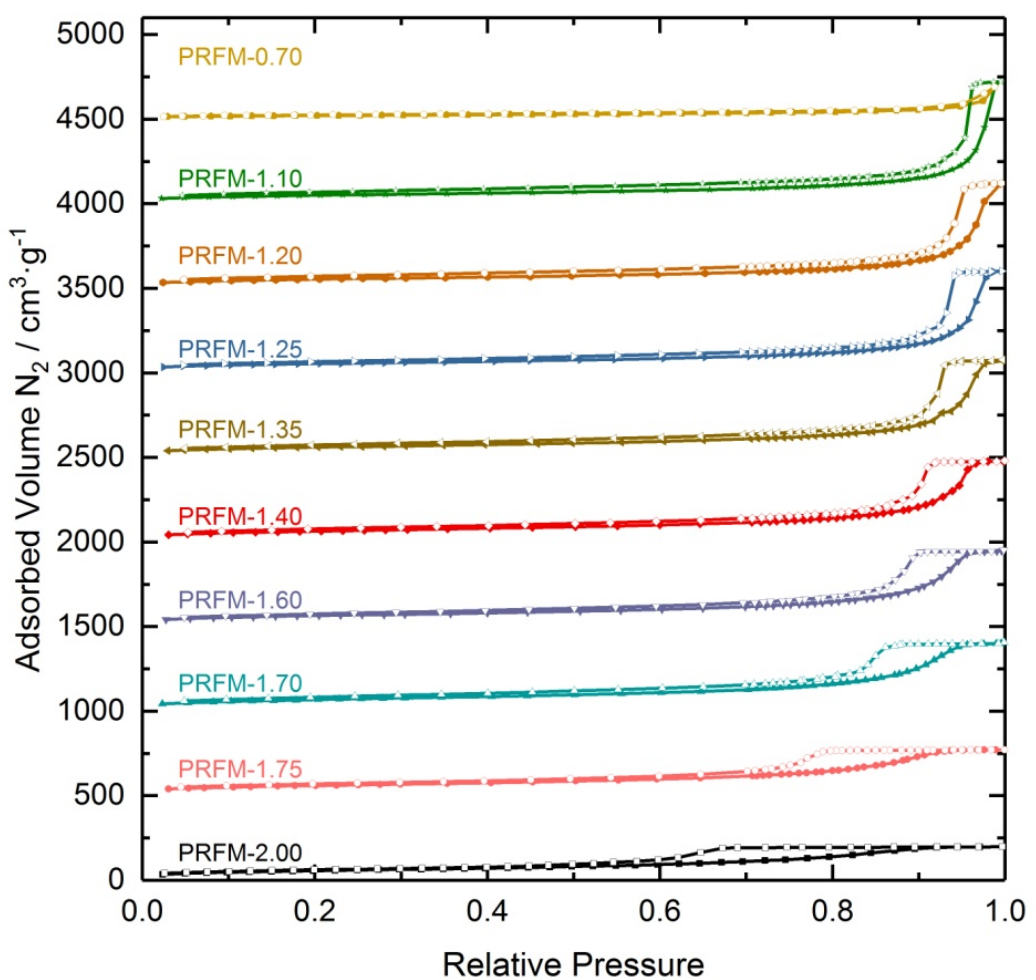

Figure S1: Nitrogen physisorption Isotherms of all synthesized porous monoliths (offset $500 \mathrm{~cm}^{3} \cdot \mathrm{g}^{-1}$ and $750 \mathrm{~cm}^{3} \cdot \mathrm{g}^{-1}$ for PRFM-0.70).

As the RF-resin has a very heterogeneous surface the results have to be viewed with caution and all methods have to be compared. The RF-resin surface chemistry is very different from the homogeneous surface chemistry of pure carbon ${ }^{1}$ and silica material, which are used as a basis for the coding of the DFT kernels. In this work only cylindrical kernels were compared even though the SEM images (see Figure 1) do not show ideal cylindrical pores since the use of slit kernels resulted in artefacts and the fit using spherical kernels did not match the measured isotherms. Exemplary shown in Figure S2 is the comparison of BJH and cylindrical carbon and silica kernels for two PRFMs. The BJH method results in the smallest mean pore sizes, but is known to underestimate the real pore size, especially for small mesopores. ${ }^{2}$ It is also obvious that the cylindrical DFT adsorption kernel provides the most realistic image of the pore system as the SEM images also show an open pore structure with a wide pore size distribution. The pore size distributions calculated from the desorption branch show a narrower pore size distribution than those from the adsorption branch, due to pore blocking and percolation effects. Additionally, the fits using the carbon kernel display a slightly smaller mean pore size than those of the silica kernel. Both, carbon and silica kernel, fit the measured isotherms very good, therefore the "real" pore size is somewhere in between. For reference of the pore size in this work, the silica desorption kernel will be used, even though it does not represent the real pore size distribution 
ideally. But, the carbon kernel is unable to fit pore system with pores larger than $30 \mathrm{~nm}$ and the pore size distributions from the adsorption branch are too broad to easily compare.
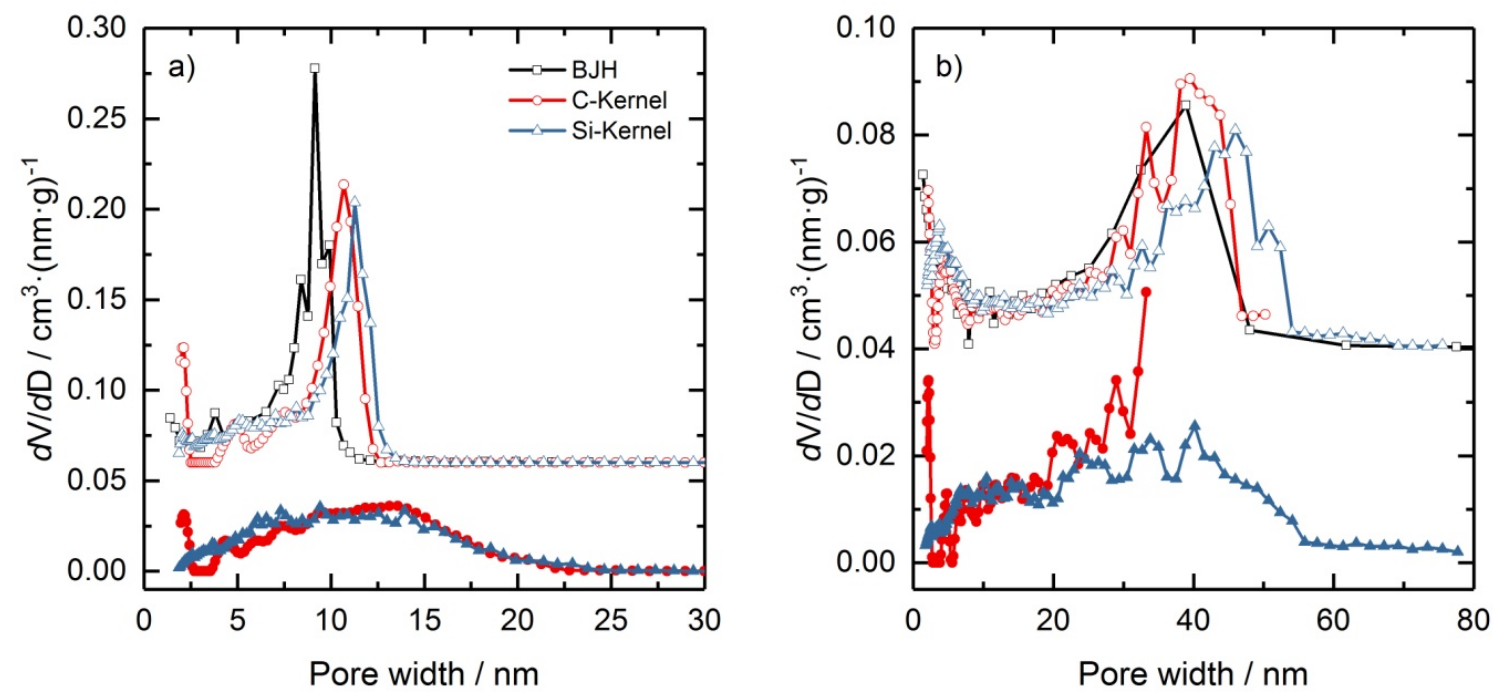

Figure S2: Comparison of pore size distributions calculated with BJH and DFT methods for (a) PRFM-1.75 and (b) PRFM-1.20. The pore size distributions calculated from the adsorption branch are shown with filled symbols (bottom) and from the desorption branch with open symbols (top) with an offset of $0.05 \mathrm{~cm}^{3} \cdot(\mathrm{nm} \cdot \mathrm{g})^{-1}$.
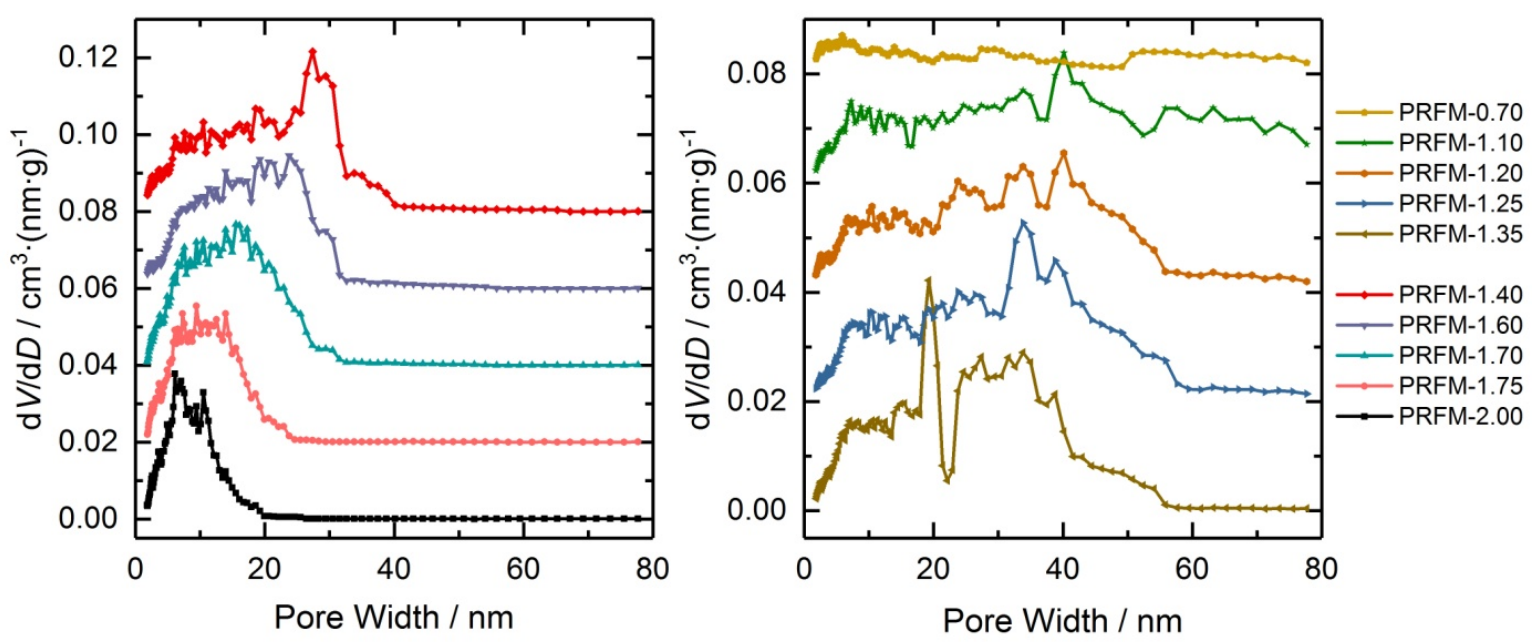

Figure S3: Pore size distributions calculated with the silica adsorption NLDFT kernel (offset $\left.0.02 \mathrm{~cm}^{3} \cdot(\mathrm{nm} \cdot \mathrm{g})^{-1}\right)$. 


\section{DSC}
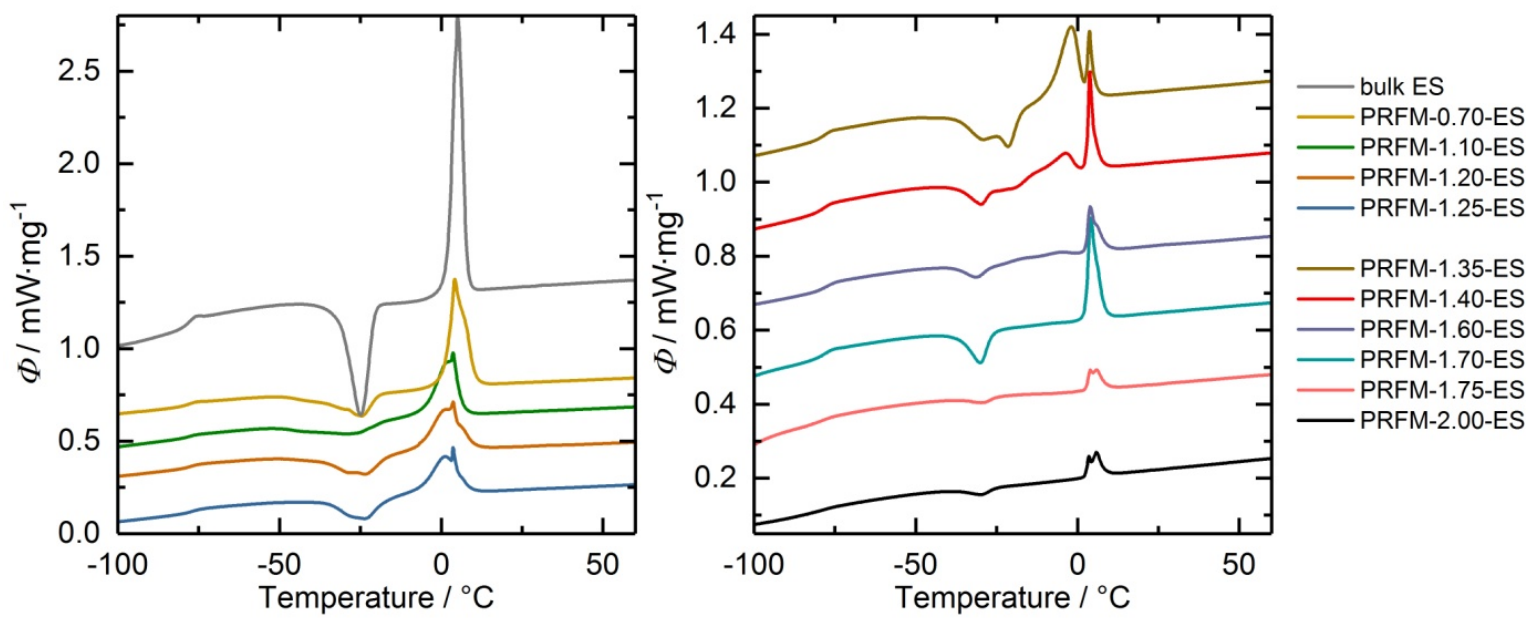

Figure S4: DSC heating curves of the porous polymer monoliths filled with electrolytic solution after quenching (cooling rate $10 \mathrm{~K} / \mathrm{min}$ and no annealing at low temperatures).

The quenched DSC heating curves (cooling rate $10 \mathrm{~K} \cdot \mathrm{min}^{-1}$ without annealing at low temperatures, Figure S4) show a glass transition at approx. $-79{ }^{\circ} \mathrm{C}$, as well as up to two exothermic peaks at approx. $-25{ }^{\circ} \mathrm{C}$ which can be attributed to solid-solid phase transition of metastable phase caused by a delayed crystallization of the electrolytic solution. 


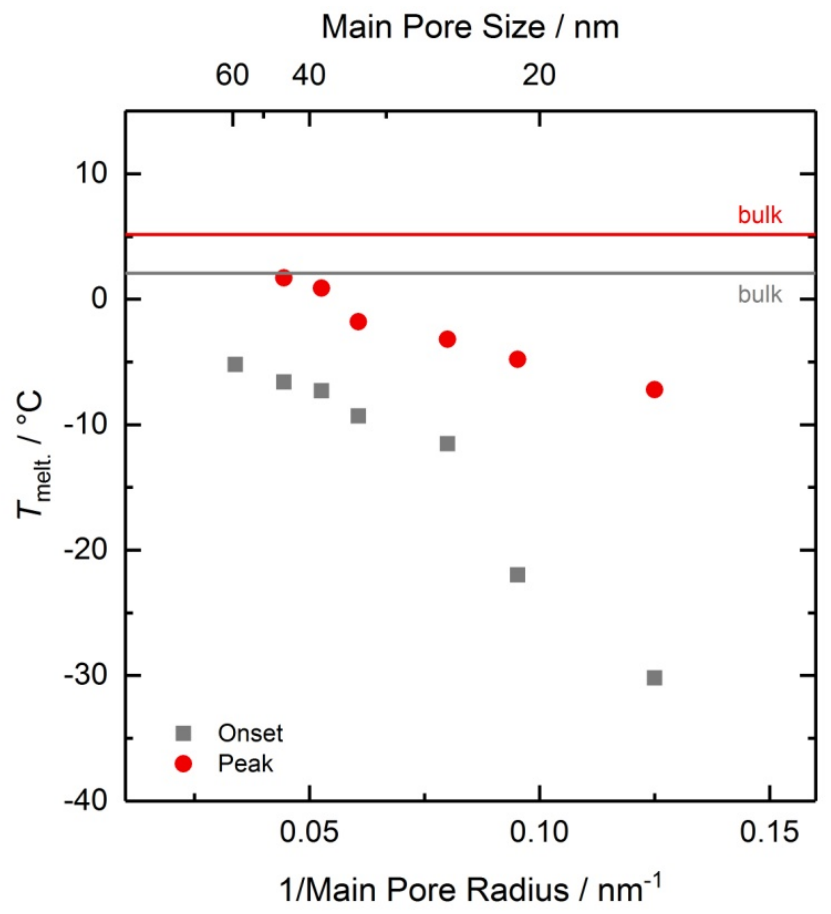

Figure S5: The onset and the peak temperatures of the melting point of confined electrolytic solution as a function of the main pore radius. The values for the bulk electrolytic solution are shown as horizontal lines.

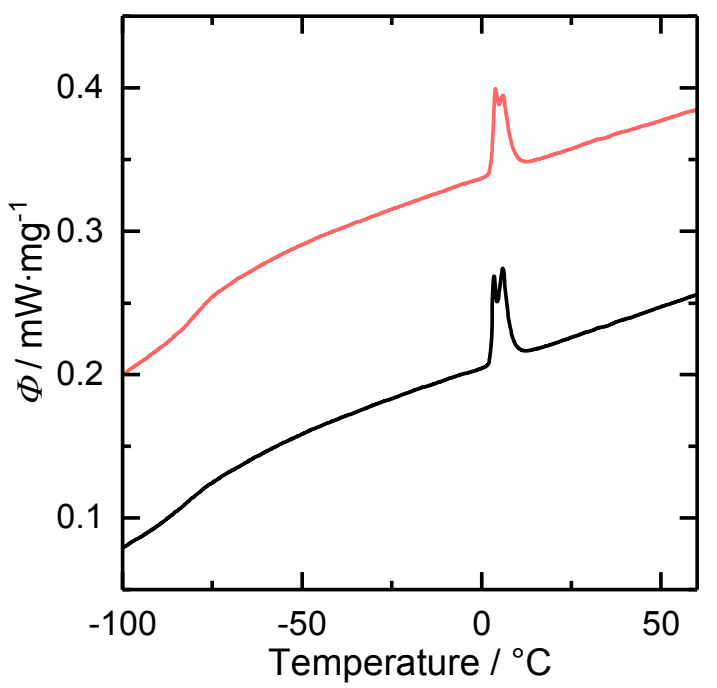

PRFM-1.75-ES

— PRFM-2.00-ES

Figure S6: DSC heating curves of PRFM-2.00-ES and PRFM-1.75-ES, which do not show a melting peak of confined electrolytic solution. 


\section{IONIC CONDUCTIVITY}
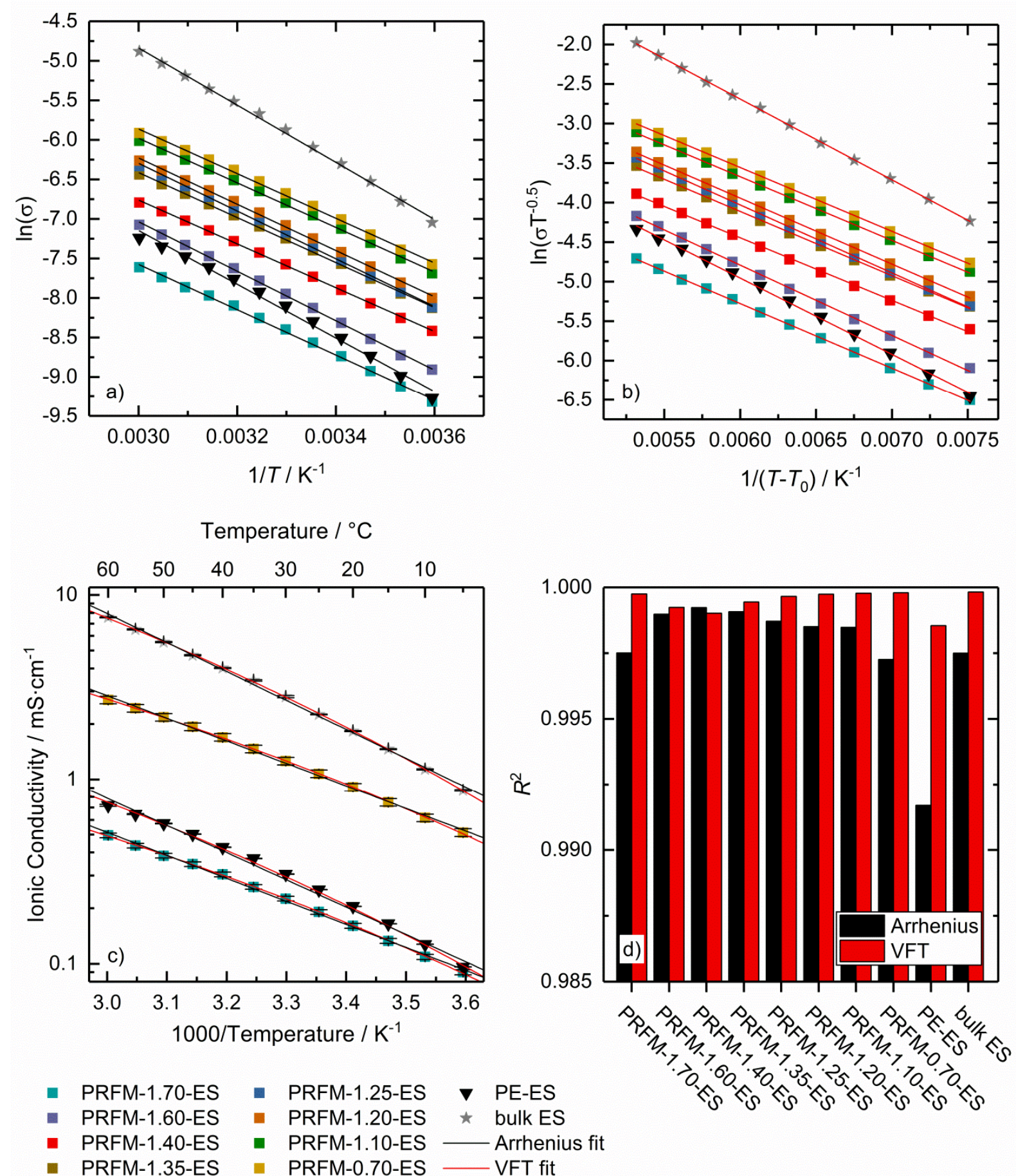

Figure S7. Fitting plots of conductivity vs. temperature based on the (a) Arrhenius and (b) VogelFulcher-Tamman equation. (c) Comparison of Arrhenius and Vogel-Fulcher-Tamman fitting curves for selected samples. The error bars consist of impedance fitting error and the error from the thickness measurement of the samples. (d) Comparison of the coefficient of determination for the Arrhenius and the Vogel-Fucher-Tamman fitting curves. 


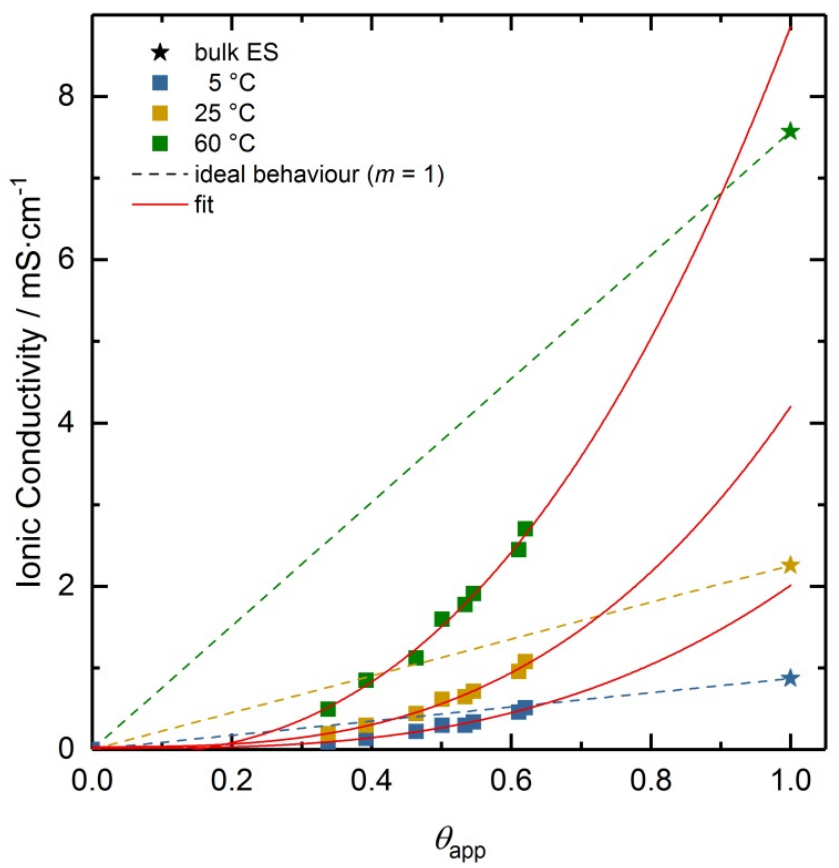

Figure S8. Correlation between $\sigma$ and $\theta_{\text {app. }}$ of PRFM- $x$-ES at 5, 25, and $60{ }^{\circ} \mathrm{C}$. The dashed line represents the ion transport behaviour inside uniform cylindrical pores of the equal diameters that are aligned parallel to the electric field $(m=1)$ with neither inter-connection nor bottleneck. The point for the bulk electrolytic solution is denoted as star symbol. 


\section{DIFFUSION COEFFICIENTS}

(a)

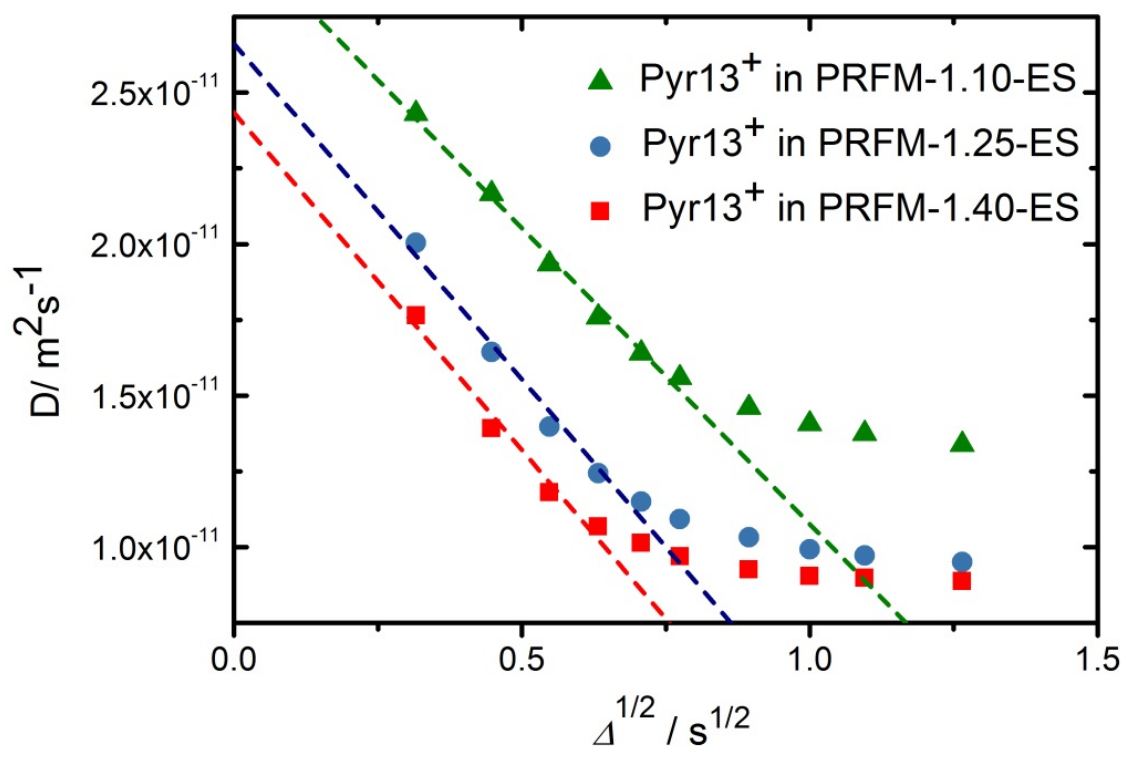

(b)

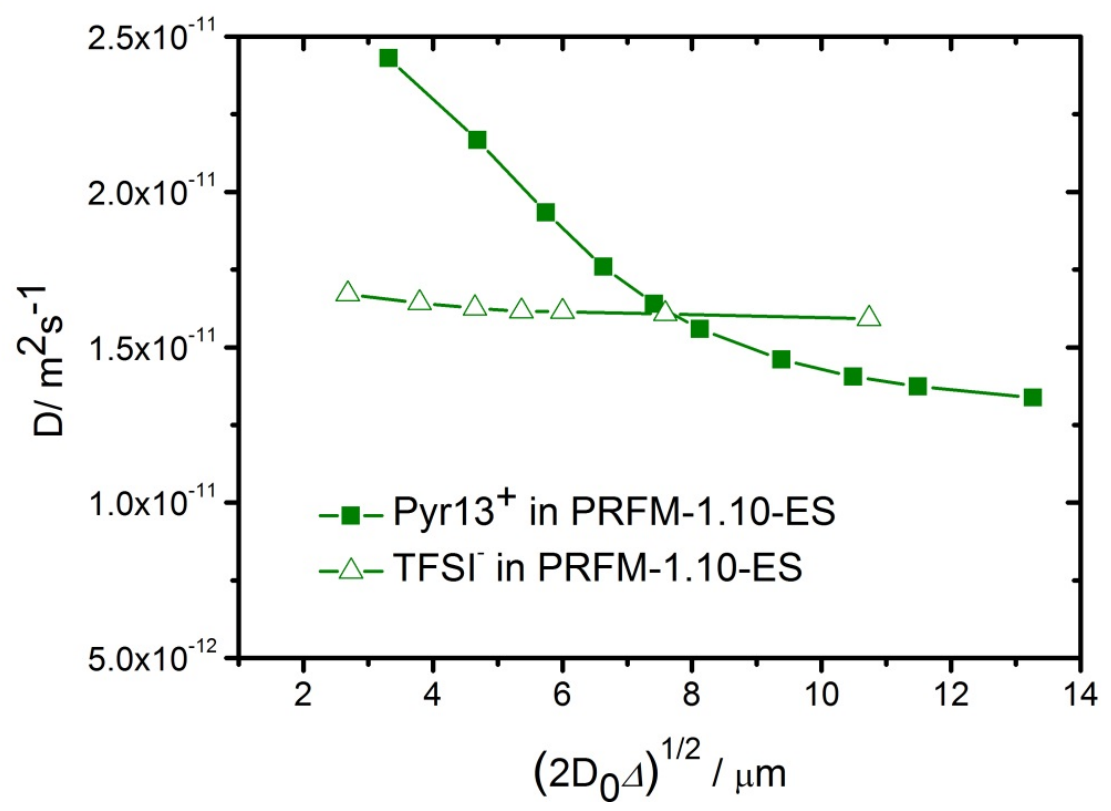

Figure S9. (a) Diffusion coefficients as a function of square root of diffusion time. To extract $\mathrm{S} / \mathrm{V}$ and $\mathrm{D}_{0}$ from the slope and intercept, respectively, time dependent diffusion region at short diffusion time is used for fitting to the Mitra equation. (b) Diffusion coefficient as a function of diffusion length $\left(2 \mathrm{D}_{0} \Delta\right) 1 / 2$. $\mathrm{D}_{\text {bulk }}$ values for cations and anions are used, respectively, as $\mathrm{D}_{0}$. 

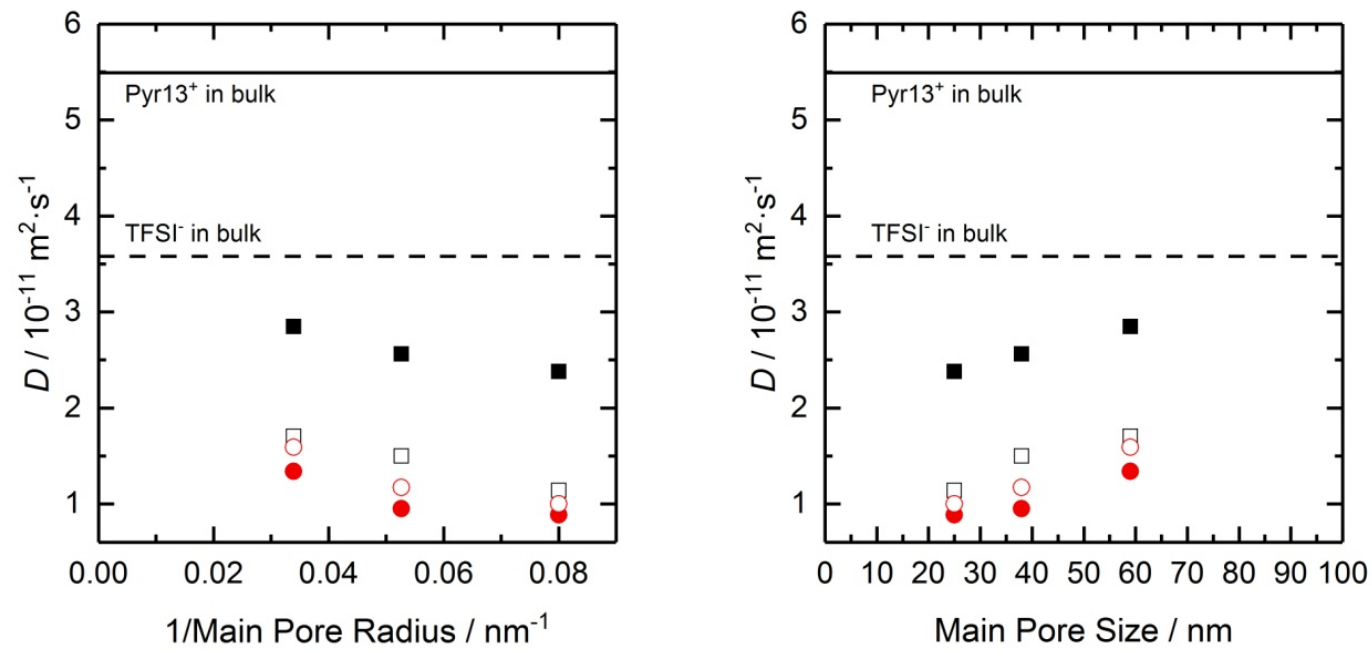

- $\operatorname{Pyr} 13^{+}, \Delta=0 \mathrm{~s}$

- $\operatorname{Pyr}_{13^{+}}, \Delta=1.6 \mathrm{~s}$

$\square$ TFSI $^{-}, \Delta=0 \mathrm{~s}$

- TFSI $^{-}, \Delta=1.6 \mathrm{~s}$

Figure S10: Influence of the main pore size on the diffusion coefficient. The diffusion coefficients for $\Delta=0 \mathrm{~s}$ were extrapolated. 


\section{6. ${ }^{7}$ LI MAS NMR OF PRFM FILLED WITH ELECTROLYTIC SOLUTION}

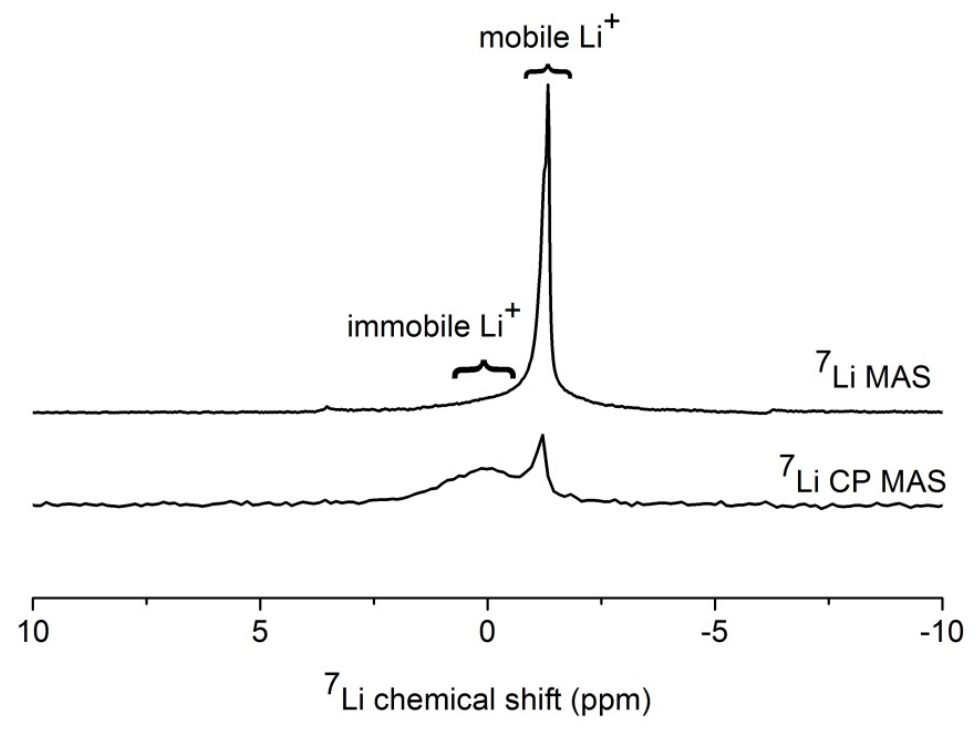

Figure S11: ${ }^{7} \mathrm{Li}$ magic angle spinning (MAS) and cross-polarization (CP) MAS NMR spectra of PRFM filled with electrolytic solution (PRFM-1.10-ES).

By applying CP MAS NMR technique, immobilized Li cations near the pore wall can be selectively enhanced, showing a broad signal at higher frequency. The relative amount of this immobile Li species is significantly lower than the mobile species as shown in quantitative ${ }^{7} \mathrm{Li}$ MAS NMR spectrum.

\section{REFERENCES}

(1) Neimark, A. V.; Lin, Y.; Ravikovitch, P. I.; Thommes, M. Quenched Solid Density Functional Theory and Pore Size Analysis of Micro-Mesoporous Carbons. Carbon N. Y. 2009, 47 (7), 1617-1628.

(2) Thommes, M.; Kaneko, K.; Neimark, A. V.; Olivier, J. P.; Rodriguez-Reinoso, F.; Rouquerol, J.; Sing, K. S. W. Physisorption of Gases, with Special Reference to the Evaluation of Surface Area and Pore Size Distribution (IUPAC Technical Report). Pure Appl. Chem. 2015, 87 (9-10), 1051-1069. 